\title{
Apoptosis-Stimulating of p53 Protein 1
}

National Cancer Institute

\section{Source}

National Cancer Institute. Apoptosis-Stimulating of p53 Protein 1. NCI Thesaurus. Code C95033.

Apoptosis-stimulating of p53 protein 1 (1090 aa, 120 kDa) is encoded by the human PPP1R13B gene. This protein plays a role in the stimulation of cellular tumor antigen p53 activity. 